\title{
Epidemiological investigation of bovine blindness syndrome in local and improved herds in Mkinga district of Tanzania
}

\author{
Emanuel S. Swai ${ }^{1}$, Esron D. Karimuribo ${ }^{2}$, Paul Y. Kisaka ${ }^{3}$, Benedeta N. Mwawado ${ }^{4}$ \\ 1. Veterinary Investigation Centre; Arusha, Tanzania; 2. Sokoine University of Agriculture, Morogoro, \\ Tanzania; 3. Muheza District Livestock Office, Tanzania; 4. Mkinga District Livestock Office, Tanzania \\ Corresponding author: Emanuel S. Swai, e-mail:ESswai@gmail.com \\ Received: 31-01-2012, Accepted: 14-03-2012, Published Online: 19-07-2012 \\ doi: $10.5455 /$ vetworld.2012.581-589
}

\begin{abstract}
Aim: A demand-driven epidemiological field and laboratory investigation of a 'bovine blindness syndrome, BBS' was conducted in Mkinga district of Tanzania during the period of June through August, 2009.

Materials and methods: Participatory epidemiological (PE) methods including focus group discussion (FGD), proportional piling and matrix scoring were used to characterize clinical signs, disease impact and risk factors for BBS as perceived by livestock keepers. PE investigation was complimented by microbiological culture of ocular discharges $(\mathrm{n}=96$ swab samples), clinical examination of animals and entomological investigation of the 'butterfly insects like' that were suspected by livestock keepers to be associated with BBS.

Results: Matrix scoring showed moderate to good agreement between informant groups on the clinical signs, risk factors, disease impact and occurrence which coincides with rainy season. Clinical examination of cattle $(n=177)$ from six villages revealed that $72(40.7 \%)$ presented discharges from eyes, of which the majority had serous discharges $(\mathrm{n}=35 ; 48.6 \%)$ while muco-purulent and dried discharges were recorded in $19.2 \%$ and $32.2 \%$ of the animals, respectively. Of the 37 cattle that were found to be blind (based on obstacle test), most were affected in the right eye and the prevalence of blindness was significantly higher in indigenous than in cross-bred cattle $(26.1 \%$ vs $5.4 \%, \mathrm{p}=0.0027)$. Entomological examination of insect specimens identified the suspected 'butterfly insects' to be moths that belong to the species Arcyophora longivalvis, reported to serve as mechanical carriers for Moraxella bovis, a bacterium that causes Infectious Bovine Keratoconjuctivitis (IBK or Pinkeye) which among others, it causes blindness in cattle. M. bovis was isolated from $83.7 \%$ of 96 samples cultured.

Conclusion: It is concluded that blindness in cattle in the area under study district was due to $M$. bovis infection. To the best of our knowledge, this is the first study in East Africa which has associated A. longivalvis moths with transmission of IBK. Appropriate disease prevention and control measures for pinkeye should be adopted in order to safeguard animal health in Mkinga.

Key words: Arcyophora longivalvis, Cattle, Moraxella bovis, Tanga, Tanzania
\end{abstract}

To cite this article: Swai ES, Karimuribo ED, Kisaka PY, Mwawado BN (2012) Epidemiological investigation of bovine blindness syndrome in local and improved herds in Mkinga district of Tanzania, Vet World, 5(10): 581589, doi: 10.5455/vetworld.2012.581-589

\section{I ntroduction}

Blindness is the condition of lacking visual perception due to physiological or neurological factors [1]. Blindness in cattle may be attributed to infectious or non-infectious causes. Infectious diseases manifested by blindness in cattle includes eye worm parasites (Thelazia spp), bacterial diseases such as Infectious Bovine Keratoconjuctivitis (IBK) and viral diseases such as infectious bovine rhinotracheitis (IBR) and Malignant Catarrhal fever (MCF) [2]. Non-infectious conditions that may cause blindness in cattle include physical trauma due to presence of foreign bodies in eyes such as grits, grasses seeds, insect's larvae, nematodes and excessive UV radiation. Blindness in cattle has also been reported to be associated with chemicals as well as plant poisoning e.g. lead poisoning, acute bracken fern poisoning. Nutritional problems such polioencephalomalacia due to thiamine deficiency and hypovitaminosis A have also been reported to be associated with cattle blindness [3-5].

It was postulated after a Participatory Rural Appraisal (PRA) survey carried out in 2006 [6] that there was high prevalence of blindness cases in cattle in Gombero and Maramba wards in Mkinga district of Tanga region. The syndrome had been perceived by livestock keepers to cause significant impact on animal health and production and; there was no control 
strategy that had been devised for that condition. It was against this background that the two veterinary researchers (ESS and EDK) were commissioned by the Mkinga district authority to undertake detailed epidemiological investigation so that interventions could be made available for controlling such a condition. Therefore the objectives of the study were: i) to assess perception, knowledge, attitude and practices on this problem in affected villages and herds, ii) to characterize the problem with respect to identification of causes (aetiology) and establishment of the magnitude of blindness problem in local and improved cattle herds and, iii) to identify risk factors associated with cattle blindness in the district.

The purpose of this study was to generate baseline epidemiological data that could facilitate the development of effective interventions for controlling such condition in the area under study.

\section{Materials and methods}

Ethical considerations: The interviewers sought verbal consent of the respondents and explained the nature and objectives of the research to the volunteers and those that were willing gave their verbal consents before the questionnaires were administered. Permission to conduct the study was granted and commissioned by the Mkinga District Council management.

Study area: This study was carried out during June through August 2009 in Mkinga district, one of the eight districts of Tanga region. The district is located in the north-east coastal area of Tanzania. The criteria for selection of the six villages within 2 wards (Maramba and Gombero) that participated in the study were the high densities of cattle (local and improved) and the high incidences of the blindness cases as identified by stakeholders during the forerunner PRA studies on animal diseases prioritization in Mkinga district [6]. Geographically the district is located between latitudes $4^{\circ} 21^{\prime}$ and $6^{\circ} 24^{\prime} \mathrm{S}$ and longitudes $36^{\circ} 11^{\prime}$ and $38^{\circ} 26^{\prime} \mathrm{E}$. The area is characterized by hot and humid tropical climate with two rainy seasons: heavy rains during the months of March, April and May, and lighter rains occurring in November and December. The mean annual rainfall varies from 500 to 1400 $\mathrm{mm} /$ year. The relative humidity ranges from $60 \%$ to $90 \%$ for most of the year. Monthly mean ambient temperatures range from $15^{\circ} \mathrm{C}$ between June to August and $33{ }^{\circ} \mathrm{C}$ between December and March. The vegetation is mainly Acacia shrubs, donm palms, wooded savanna with short grass.

Cattle husbandry system: The main economic activities in Mkinga district are crop production, livestock keeping, trading as well as fishing particularly along the Indian coastal areas of the district. Statistics of livestock in the district show that Mkinga has 29,990 indigenous cattle, 1,962 improved cattle, 27,864 goats and 7,055 sheep [7]. The study animals were indigenous breeds of cattle, Tanzania short horn zebu (TSHZ) and their crosses with taurine breeds reared under intensive and extensive husbandry systems of which the latter allows free grazing, usually mixed with livestock from other villages. The breeding system used is natural mating, with bulls running freely with females all year round.

Data collection: The PE studies consisted of focal group discussions with livestock keepers, for which a village was the unit of analysis and key informant interviews. The focal group discussions took place in 6 villages, comprising of an average of 5-8 informant groups. In each village, focal groups comprising between seven and 20 people per group, most of whom were men and some of whom were ethnically Maasai, participated in the study. During the focal group discussions, a variety of PE tools, previously described in the literature $[8,9]$ were utilized to encourage active participation of each member in the groups. These PE tools were complimented by direct observation of cattle herds and their environment as well as physical examination of animals.

Semi-structured interviews: These were used to collect general information about knowledge and experience with respect to history of blindness in Mkinga district, clinical presentation, reaction and action taken after seeing cases, effects and consequences of diseased cattle were assessed. The interviews were guided by semi-structured questionnaire that was a pre-tested and adjusted prior to conduct of detailed field investigation. Interviews were conducted using the national Swahili language.

Proportional piling: This tool was used to rank livestock species by numbers and relative contribution to livelihoods, using the method described in the literature [9]. During this procedure, participants first listed livestock animal species they had and a circle was drawn on the ground representing each species. Participants allocated 100 counters (beans or maize seeds) to the circles according to the relative numbers of each species. The exercise was then repeated, except this time participants were asked to allocate the counters in proportion to the relative contribution each species made to their livelihoods. Follow-up 
questioning explored the range of benefits that each livestock species provided.

Perceived association between diseases and clinical signs; and risk factors : Informal interviews with livestock keepers were used to identify five most important bovine blindness related diseases to be used in the matrix scoring along with BBS using the proportional piling technique $[9,10]$. Cattle diseases or syndromes identified by livestock keepers were the East Coast fever (ECF), anaplasmosis, trypanosomosis, Lumpy Skin Disease (LSD), Insect/Butterflyassociated blindness (BAB) (locally called 'upofu vipopo' or 'samburimburi' in Swahili and Maasai, respectively) as well as accidental trauma or snake bite. Clinical signs reported by livestock keepers to be associated with eye problems in cattle were excessive lacrimation, swollen eyes, opacity of eye (described as cloudy central area of the eye called 'mtoto wa jicho' in Swahili), blindness, rough hair coat, loss of body weight (initially but later on the animal re-gains weight) and depression. Simple matrices were constructed on the ground. Various clinical signs formed the $y$-axis and five common diseases/ syndromes, one of which was $\mathrm{BAB}$, formed the $\mathrm{x}$-axis. Likewise, risk factors formed the $\mathrm{y}$-axis and diseases/ syndromes formed the $\mathrm{x}$-axis. Twenty counters were allocated for each disease and the participants were asked to divide the counter in relation to the relative importance of each symptoms/clinical signs or risk factors played in the disease.

Key-informant interviews: These were conducted with various officials who had been involved in the management of the BBS, such as livestock field extension officers who are commonly involved in delivery of animal health services in rural areas of Tanzania. Other category interviewed was the village leaders in the study area.

Eye swab collection and blindness assessment: Swabbing of eyes for bacteriological examination was carried out using sterile swabs, which were placed immediately into sterile Cary-Blair transport medium tubes. In total, 96 swabs from left (46) and right (50) eyes were collected for bacteriological examination in order to isolate and identify causative agents responsible for eye lesions in cattle on study herds. After proper labeling, the tubes were placed in cool boxes with cold ice-packs and thereafter stored under refrigeration temperature (at $4{ }^{\circ} \mathrm{C}$ ) before further processing in the laboratory.

Assessment of the presence and degree of blindness in each animal was conducted using standard test for blindness which include menace (blink) reflex and obstacle test [1, 11], Figure 1]. Due to consistent mention of involvement of trypanosomosis in causation of eye blindness in cattle by livestock keepers during PE study, blood smears were also collected from study animals to assess magnitude and association of haemoparasitic conditions (main focus being trypanosomosis) with eye problems in the study animals.

Bacteriological isolation and identification: All 96 swabs for bacteriological procedures and blood smear for blood-borne parasitological examinations were processed at the Faculty of Veterinary Medicine of the Sokoine University of Agriculture (SUA). The swabs were directly streaked on 5-10\% Blood agar (BA) and MacConkey agar (MCA) and incubated at $37{ }^{\circ} \mathrm{C}$ for 24 hours. Bacterial isolates were examined for their macro- and micro-morphology growth characteristics and identification was carried out based on standard procedure [12].

Entomological identification of insects associated with cattle blindness: The insects collected were placed in a container containing $70 \%$ alcohol before being transported to the Entomology laboratory at the Faculty of Veterinary Medicine, Sokoine University of Agriculture for further identification. Gross appearance was recorded before the specimens were subjected to detailed entomological examination and identification using stereo microscope. Identification keys were used to arrive at accurate diagnosis of the submitted insects using the Gordon's key for identification of insects e.g. presence of wings, number of wing pairs, presence of scales on wings and body surface [13].

Data management and statistical analysis: A database was constructed in Epi-Info ${ }^{\circledR 10}$ to store the data. Descriptive analyses to characterise both the dependent and independent variables collected in the study were conducted using queries executed in EpiInfo. Magnitude of association between risk factors and blindness problem was measured by the Relative Risk (RR) $[14,15]$. The Chi-square test was used to assess significance of difference in proportions of different groups examined [14]. The critical probability of $p<0.05$ was used as criteria for statistical significance throughout data analysis.

\section{Results}

Relative herd structure and importance: The largest livestock population in the study area was cattle $(54.5 \%)$, followed by goats $(27.2 \%)$ and sheep 


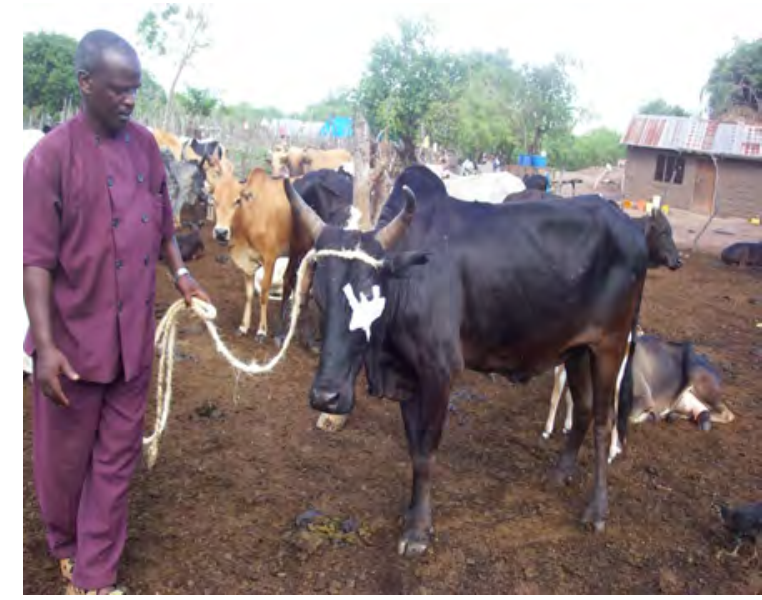

Figure-1. Assessment of blindness by performing an obstacle test when an animal with left eye patched was lead into obstacle

(18\%). Other livestock kept, however in small numbers, were donkeys, dogs and chicken. In all surveyed villages, livelihoods depended largely on livestock and crop production. Cattle were the livestock species that made by far the greatest contribution to livelihoods. For all livestock species, the main benefit derived from livestock was reported to be food, which included meat and milk. The second most important benefit was income from sales of surplus animals or produce and payment of dowry with cattle or goats. In total, 177 cattle ( $24.3 \%$ crossbred and $75.7 \%$ indigenous) of different age groups, and sexes (i.e. $70.6 \%$ females and $29.4 \%$ males) were examined for eye problems. Of the sampled cattle, $23(13 \%)$ were classed as bulls, $51(28.8 \%)$ as cows, $27(15.2 \%)$ as in-calf heifers, 26 $(14.7 \%)$ as yearling, $15(8.5 \%)$ as weaners and 35 $(19.7 \%)$ as suckling calves. Of the six villages that participated in this investigation, only Mavovo (in Maramba ward) had higher number of crossbred cattle belonging mainly to smallholder dairy farmers in that ward.

I nformants knowledge, perception and description of BBS: Key informants and district officials perceived and reported cattle blindness as an animal health problem that was reported by livestock keepers in the past three years before this study. The informants also acknowledged that the blindness problem was still occurring in the district during the study. From livestock keepers' information, the problem was believed to be associated with rains so its occurrence was ussually coincide with the rainy season (during both short and long rains; Figure 2). With respect to

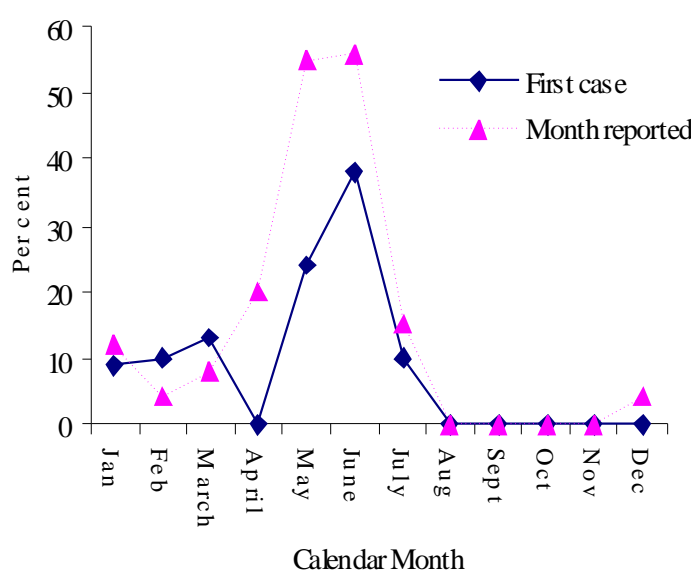

Figure-2. Seasonal occurrence of cattle blindness in study areas based on the month when first case was recorded or perceived month of occurrence

cause of this condition, respondents considered special insects (butterflies or moths) to be involved in causation of the blindness condition in cattle. These insects were noted to prefer facial area of cattle especially at night. From livestock keepers' information, there is good coincidence between the occurrence of blindness problem and increased insect activity during the rainy season. These insects are not seen during day time, so they can only be trapped during night hours. With regards to signs shown by affected cattle, it was reported that the condition was characterized by changes in the shape of affected eyes, presence of opacity and finally blindness. In most cases, the problem starts as unilateral (i.e. one eye only affected) but later on the second eye is also affected. The following was considered as chronology (order) of development of clinical signs in affected animals: $1^{\text {st }}$ - Excessive lacrimation in eyes attacked by the butterflies. Usually lacrimation starts as unilateral sign but later it becomes bilateral when both eyes are affected. $2^{\text {nd }}-$ Serous lacrimation becomes mucopurulent and with time, the discharge dries up along medial canthi, $3^{\text {rd }}$ - The eyes become swollen and eyelids close. When eyes are forced to open, whitish 'cloudy' lesion (opacity) is seen at the centre of affected cornea, $4^{\text {th }}-$ Blindness comes in and the animal at the beginning loses weight due to inability to see and feed on grasses. Different stages of pathological changes in eyes of affected animals, as recorded during fieldwork, are shown in Figure 3a-c.

Local characterization of BBS: The key informants proved to be knowledgeable at recognizing symptoms 


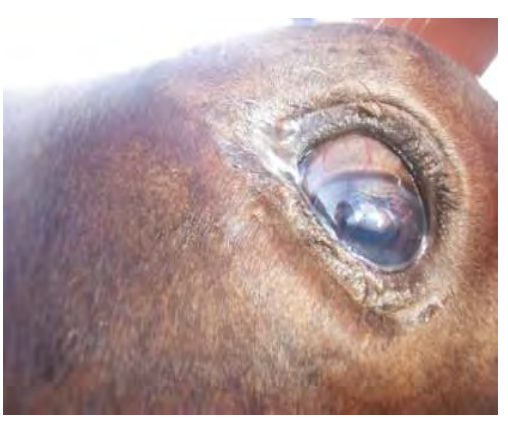

Fig-3a. Unilateral (left eye) mucopurulent discharge in animal examined

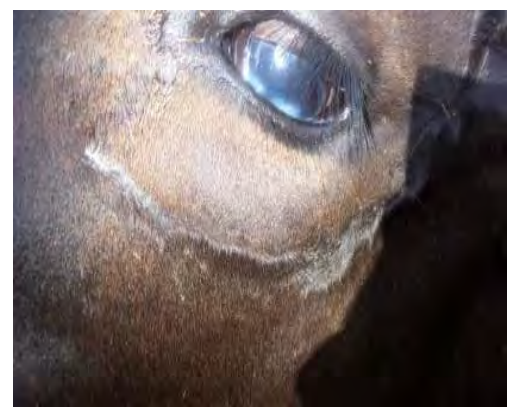

Fig-3b. Initial (mild) development of corneal opacity in one eye of affected animal

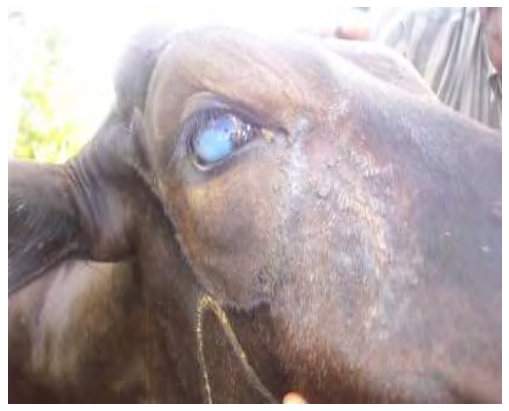

Fig-3c. Chronic corneal opacity and dried muco-purulent discharges in affected cattle

Table-1. Association between disease conditions characterized by blindness and clinical signs based on scale of $0-20$ ( where $0=$ absent and 20 present)

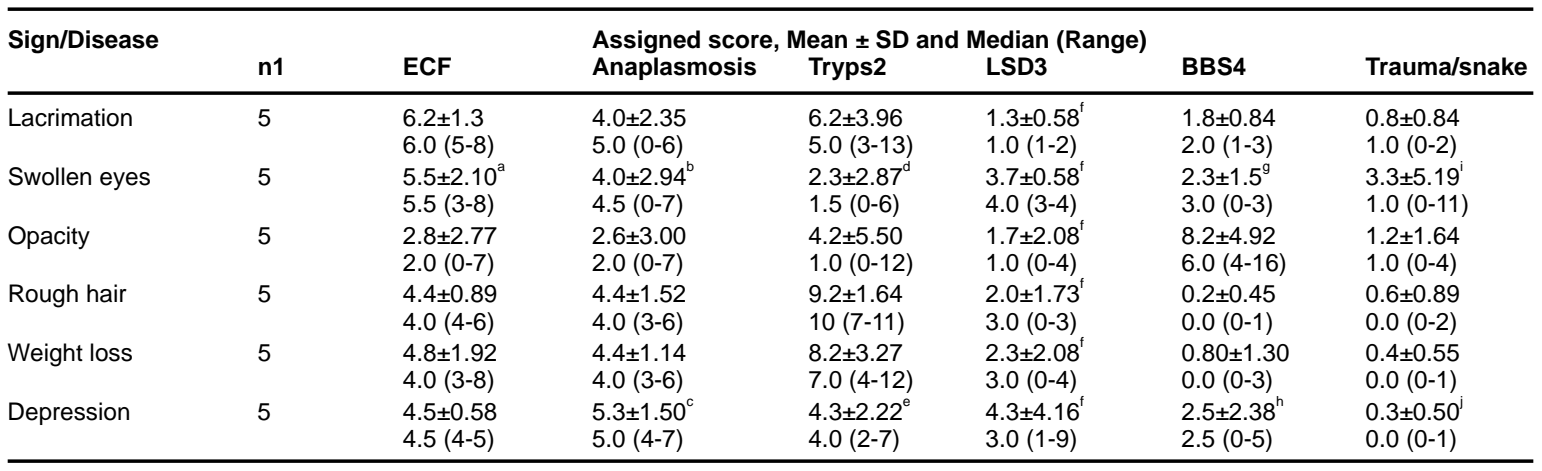

1: $\mathrm{n}$ represents the number of Focus Groups in five villages that responded except where is indicated otherwise. 2: Tryps stands for trypanosomosis. 3: LSD stands for lumpy skin disease. 4: BBS stands for bovine blindness syndrome. a: Only four groups reported swollen eyes as a clinical sign associated with ECF. b: Only four groups reported swollen eyes as a clinical sign associated with anaplasmosis. c: Only four groups reported depression as a clinical sign associated with anaplasmosis. $d$ : Only four groups reported swollen eyes as a clinical sign associated with trypanosmosis. e: Only four groups reported depression as a clinical sign associated with trypanosmosis. f: Only three of the five groups mentioned lumpy skin disease as condition characterized by eye problems. g: Only four groups reported swollen eyes as a clinical sign associated with BBS. h: Only four groups reported depression as a clinical sign associated with BBS. i: Only four groups reported swollen eyes as a clinical sign associated with groups reported depression as a clinical sign associated with BBS. i: Only four groups reported swollen ey
trauma/snake bite. jOnly four groups reported depression as a clinical sign associated with trauma/snake bite

of BBS in their cattle herds, and also in identifying risk factors associated with the disease. The informants consistently and correctly listed symptoms such as opacity, swollen eyes and lacrimation as being indicative of BBS, and also correctly associated the disease with contact with butterfly/moth and pasture. In addition, they correctly and strongly associated appropriate disease sign with other diseases; for example weight loss and rough hair with trypanosomosis and lacrimation with ECF. The results of matrix scoring for BBS and other diseases are shown in Table- 1 .

I mpact of BBS on herd owner's livelihood: Ranking diseases of cattle characterized by blindness by impact using matrix scoring revealed that ECF was ranked as the most economic important disease in the area under study. Pre-determined effects of diseases that were perceived to be of economic importance included: animal deaths, reduced milk yield, lowered value of infected animals, high treatment costs, abortion induced by the disease and stress exerted on animal owner. Other diseases and their scores in descending order were anaplasmosis, trypanosomosis, LSD and snake bite/trauma. Based on 0-20 scale, livestock keepers in the area under study ranked these effects as shown in Table 2 .

Clinical examination of affected eyes: The magnitude of animals with history of eye problems in different villages is shown in Figure 4. Overall, out of 177 animals examined, $72(40.7 \%, 95 \% \mathrm{CI}=33.4-$ 48.3) had history of eye problems. Machimboni and Mavovo villages had significantly higher number of animals with history of eye problems as reported by livestock keepers. It was further noted that a significantly higher number of indigenous cattle (47.8\% of 134 cattle examined) had history of eye 
Epidemiological investigation of bovine blindness syndrome in local and improved herds in Mkinga district of Tanzania

Table-2. Effects of disease conditions associated with eye problems

\begin{tabular}{|c|c|c|c|c|c|c|c|}
\hline Sign/Disease & n1 & ECF & $\begin{array}{l}\text { Assigned score } \\
\text { Anaplasmosis }\end{array}$ & $\begin{array}{l}\text { Mean } \pm S \\
\text { Tryps } 2\end{array}$ & $\begin{array}{l}\text { Median (Range) } \\
\text { LSD3 }\end{array}$ & BBS4 & Trauma/snake \\
\hline Mortality & 5 & $\begin{array}{l}9.6 \pm 2.1 \\
(1-12)\end{array}$ & $\begin{array}{l}4.0 \pm 2.35 \\
5.0(0-6)\end{array}$ & $\begin{array}{l}2.8 \pm 1.3 \\
(2-5)\end{array}$ & $\begin{array}{l}1.0 \pm 0.1 \\
(0-2)\end{array}$ & $\begin{array}{l}0.4 \pm 0.2 \\
(0-1)\end{array}$ & $\begin{array}{l}0.8 \pm 0.83 \\
(0-2)\end{array}$ \\
\hline Reduced quality & 5 & $\begin{array}{l}5.2 \pm 3.0 \\
(2-10)\end{array}$ & $\begin{array}{l}2.6 \pm 3.00 \\
2.0(0-7)\end{array}$ & $\begin{array}{l}7.2 \pm 3.5 \\
(3-11)\end{array}$ & $\begin{array}{l}2.4 \pm 1.3 \\
(0-7)\end{array}$ & 0 & $\begin{array}{l}0.2 \pm 0.4 \\
(0-1)\end{array}$ \\
\hline Abortion & 5 & $\begin{array}{l}9.4 \pm 2.7 \\
(6-13)\end{array}$ & $\begin{array}{l}5.0 \pm 2.5 \\
(2-9)\end{array}$ & $\begin{array}{l}7.2 \pm 2.6 \\
(5-11)\end{array}$ & $\begin{array}{l}2.0 \pm 0.9 \\
(0-2)\end{array}$ & $\begin{array}{l}0 \\
0\end{array}$ & $\begin{array}{l}0 \\
0\end{array}$ \\
\hline Stress owner & 5 & $12.4 \pm 4.5$ & $5.6 \pm 3.5$ & $0.6 \pm 1.3$ & $1.4 \pm 3.1$ & 0 & 0 \\
\hline
\end{tabular}

1: ECF stands for East coast fever, 2: Tryps stands for trypanosomosis, 3: LSD stands for lumpy skin disease, 4BBS stands for bovine blindness syndrome

problems as compared to crossbred animals (18.6\% of 43 cattle examined $)(\mathrm{p}=0.0007)$.

Severity of blindness during herd visits: The most common signs noted during animal examinations of the 72 cattle were: serous discharges $(48.6 \%)$, mucopurulent and dried discharges were recorded in 19.2\% and $32.2 \%$ of the animals, respectively. The conjunctival and corneal lesions were distributed more or less equally between the left and right eyes. Based on obstacle and menace reflex tests, 37(20.9\%) and $13(7.3 \%)$ animals respectively were classified as blind and right eyes were significantly more affected than left eyes $(P<0.05)$. It was noted that the prevalence of blind cattle was higher in indigenous $(26.1 \%)$ than in cross-bred $(5.4 \%)$ cattle $(\mathrm{p}=0.0027)$.

Bacteriological findings: All 96 swabs from eyes subjected to bacteriological culture had at least one bacterium isolated from them. The majority $(83.7 \%)$ of isolates belonged to Moraxella bovis, the causative agent of Infectious Bovine Keratoconjuctivitis (IBK). Of the cultured samples, $2(2.1 \%)$ had mixed infections between M. bovis and Staphylococcus spp.

Entomological findings: Based on entomological examinations, the butterfly-like insects alleged to be responsible for causing blindness in cattle were identified to the order Lepidoptera. This was based on presence of siphoning mouthparts and wings covered in overlapping scales. Further examination and history of activity at night confirmed that the insects were moths belonging to the species Arcyophora longivalvis. This species is classified as follows [1, 16]: Kingdom: Animalia, Phylum: Arthropoda, Class: Insecta, Order: Lepidoptera, Family: Noctuidae, Genus: Arcyophora, Species: Arcyophora longvalvis Guenée 1982. Local name: 'Vipopo (Digo)' or 'Samburimburi (Maasai)'.

Management of clinical cases of blindness:
Different approaches were reported by 32 livestock keepers to be used to attend to sick animals in herds affected by cattle blindness. The most common approaches practiced were: application of snail shells ash (48\%), donkey urine (4\%), branding around the eyes (58\%), toothpaste (10\%), Trypanocides (12\%), Anti-theilerials $(6 \%)$ and use of Veterinary drugs $(80 \%)$. The majority of sick animals were reported to be attended by livestock keepers themselves although a few cases were also attended by either agriculture and livestock extension officers or community-based animal health workers. The most common practices used by these cadres were: using veterinary drugs (antibiotic powder, solutions or eye ointments), branding around eyes and use of ash obtained after burning snail shells. Common veterinary drugs reported to be used were oxytetracycline (OTC) or penicillin (human preparation). Other less common practices mentioned included the use of tooth paste, anti-theilerials (when ECF was a suspected cause), trypanocides (when trypanosomosis was a suspected cause) or even the use of donkey urine.

Blood borne parasites: Of all 177 blood smear specimens examined, none was found to have common haemoparasites such as trypanosomes, ECF piroplasms, anaplasma or babesia.

\section{Discussion}

The study showed that livestock keepers described clinical and epidemiological features of BBS according to the typical descriptions of the disease in veterinary descriptions and textbooks $[1,5]$. Perceptions of the clinical signs, disease impacts and risk factors were all consistent with veterinary thinking. These epidemiological perceptions were very well supported by the entomological survey and bacteriological culture findings. Compared to other bovine blindness diseases investigated in this study, 


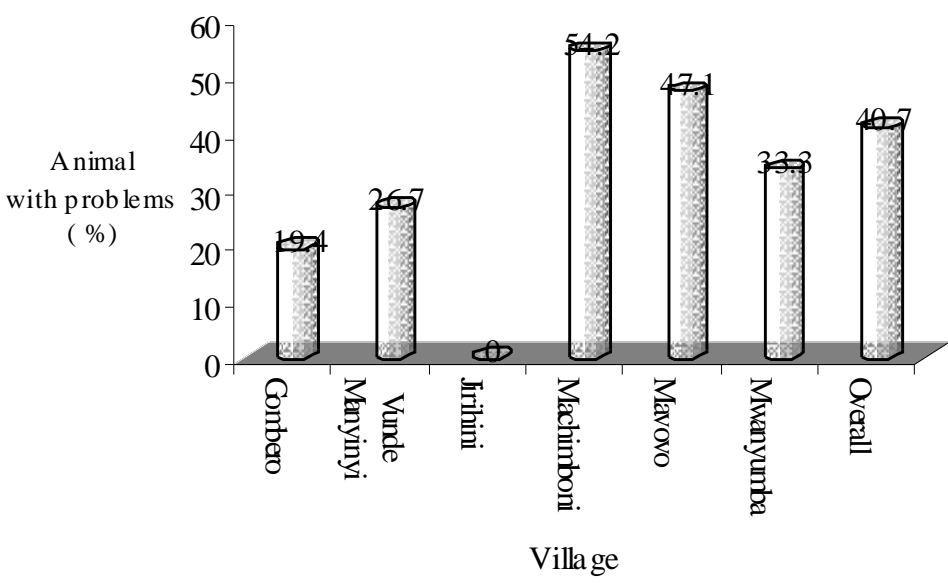

insects (butterfly) alleged to be responsible for causing blindness in cattle were identified to the order Lepidoptera. Arcyophora spp. are nocturnal moths commonly found in Africa [19]. These insects have been reported to be responsible for transmission of Moraxella bovis, a bacterium causing infectious bovine keratoconjuctivitis (IBK or pinkeye) in different countries. In Africa, these moths have been reported to serve as mechanical vector of Moraxella spp in Ivory Coast and Namibia [19, 20].

In all 177 examined blood smear no parasite was found, absence of such parasites does not necessarily indicate total absence of these parasites as the method used (diagnostic microscopy) is known to have its limitation in detection of such parasites due to its low sensitivity[21, 22]. Other factors such as diurnal fluctuations of parasitaemia, and hence concentrations of parasites in blood smears, may also explain lack of infected samples under the current investigation.

Given the diversity of various approaches and drugs used to manage blind cattle, it was difficult to identify which ones were likely to be effective. However, continued presence and reporting by farmer of cattle blindness as a problem that required investigation, it was obvious that the above methods were not effective in controlling the disease. From past experience in Tanzania, Mujuni et al. [18] recommended early diagnosis, intervention and application of sub-conjuctival antibiotics for managing clinical cases of Infectious Bovine Keratoconjuctivitis. Given isolation of Moraxella bovis in most cases investigated in this study, the above recommendations remain applicable to the current situation in Mkinga district.

\section{Conclusion}

Cattle blindness experienced in different villages in Mkinga district.

Based on entomological examinations, the 
of Mkinga district are, to a large extent, caused by Moraxella bovis. Based on that, the disease condition involved is Infectious Bovine Keratoconjuctivitis (IBK). The 'butterflies' suspected to be involved in transmission of cattle blindness are nocturnal moths of the species Arcyophora longivalvis. Risk factors identified to be associated with cattle blindness include rainy season when insect activity is increased. Indigenous cattle appeared to be more affected by the blindness than crossbred cattle, most likely due to pasture grazing where these animals are exposed to long grasses, dusty environment and insects which are predisposing factors for IBK in different countries.

\section{Author's Contribution}

Conceived and designed the study: ESS \& EDK. Conducted field surveys: ESS, EDK, and PYK \& BNM. Analyze samples: EDK. Analyzed the data: ESS \& EDK. Wrote the paper: ESS \& EDK. All authors read and approved the final manuscript.

\section{Acknowledgements}

We would like to acknowledge support of different individuals who facilitated field and laboratory works, which lead to production of this paper. We are particularly thankful to Mr P.S.M. Ngaponda (the District Executive Director, Mkinga), and Mr E. Hume (SMS Livestock Production-Mkinga district) who provided helpful administrative support throughout the study. Mr P. Mkuchu and L. Kindamba facilitated bacteriological and entomological works, respectively at SUA.

\section{Competing interest}

Authors declares that they have no competing interest.

\section{References}

1. Blood, D. C.; Radostits, O. M.; Gay, C.C.; Hinchcliff, K. W., Constable, P. D. (2007). Veterinary Medicine: A textbook of the diseases of cattle, horses, sheep, pigs and goats. $10^{\text {th }}$ edn, Philadelphia, Saunders Ltd: 2065

2. Davidson, H. J.; Stokka, G. L., Van Boening, J. (2008). Pinkeye: Infectious Bovine Keratoconjuctivitis. Kansas State University Agricultural Experiment Station and Cooperative extension Service. Online at http://www.oznet.ksu.edu/library/ LVSTK2/MF2210.PDF (accessed 22 December 2010).

3. Booth, A.; Reid, M., Clark, T. (1987). Hypovitaminosis A in feedlot cattle. Journal of American Veterinary MedicalAssociation, 190: 1305-1308.

4. Donkersgoed, J., Clark, E. G. (1988). Blindness caused by hypovitaminosis A in feedlot cattle. Canadian Veterinary Journal, 29: 925-927.

5. Aiello, S. E., Mays, A. (Eds) (1998). The Merk
Veterinary Manual. 10 ${ }^{\text {th }}$ Edition. Merck \& Co., Inc. Whitehouse Station, N.J., USA.

6. Anonymous (2006). Diagnostic Participatory Rural Appraisal report for livestock keepers disease constraints in Mkinga Division, Muheza, Tanga, Tanzania, EZCORE internal report, July 2006: pp.14-32.

7. Anonymous (2009). Agriculture and livestock annual report, Mkinga district, Tanzania: pp. 23-40.

8. Catley, A., (2005). Participatory Epidemiology: A guide for Trainers. African Union/Interafrican Bureau for Animal Resources, Nairobi. Online at http://www. participatoryepidemiology. info/copy/pdf (accessed on 20/1/2012).

9. Catley, A., (2006). The use of participatory epidemiology to compare the clinical ad veterinary knowledge of pastoralist and veterinarians in East Africa. Trop Anim Health Prod 38:171-182.

10. Mariner, J. C, Paskin, R. (2003). Manual on participatory epidemiology. Methods for the collection of action-oriented epidemiological intelligence. Food and Agriculture Organization of the United Nations (FAO) Animal Health Manual No. 10. FAO, Rome.

11. UCVOS, University of California Veterinary Ophthalmology Service 2008 Examination of the eye. Online at http://www.vetmed.ucdavis.edu/courses/ vet_eyes/conotes/con_chapter_1.html, (Accessed 05/ 08/2010).

12. Carter, G. R., Wise, D. J. (2004). Essentials of Veterinary Bacteriology and Mycology. $6^{\text {th }}$ edn. Blackwell Publishing. London: 45-60.

13. Earth-Life Web Productions. (2008). Gordon's Key to the identification of insects to order. Online at http://www.earthlife.net/insects/orders-key.html (accessed 19 December 2010).

14. Kirkwood, B. R., Sterne, A. C. (2003). Medical Statistics. $2^{\text {nd }}$ edn. Blackwell Science. Oxford: 67-120.

15. Thrusfield, M. (1995). Veterinary epidemiology. Blackwell Science Ltd. Oxford: pp.234-238.

16. Kemal, M., Koçak, A. O. (2007). Synonymous checklist of the South African Lepidoptera. Cesa Publications on African Lepidoptera.

17. Takele, G. A., Zerihun, A. (2000). Epidemiology of Infectious Keratoconjunctivitis in Cattle in South-east Ethiopia. Journal of Veterinary Medicine A, 47:169173.

18. Mujuni, P. F.; Mwamengele, G. L. M.; Minga, U. M., Posada, G. A. (1990). Infectious bovine keratoconjuctivitis in a dairy farm in Tanzania. Tanzania. Vet Bull, 10: 59-69.

19. Harwood, R. F., James, M. T. (1979). Entomology in human and animal health. McMillan Publishing Co., Toronto: 114-115.

20. Nicolet, J., Buttiker, W. (2008). Observations on infectious keratoconjuctivitis of cattle in Ivory Coast. Study on the eye-frequenting Lepidoptera as vectors. Revue d'Elevage et de Medecine Veterinaire des Pays Tropicaux. Online at http:// 
Epidemiological investigation of bovine blindness syndrome in local and improved herds in Mkinga district of Tanzania

www.cababstractsplus.org/abstracts/Abstract.aspx? $\mathrm{AcNo}=19750529942$ (accessed 19 August 2010).

21. Mugasa, C. M.; Schoone, G. J.; Ekangu, A.; Lubega, G. W.; Kager, P. A., Schallig, H. D. F. H, (2008). Detection of Trypanosoma brucei parasites in blood samples using real-time nucleic acid sequence based amplification. Diagnostic Microbiology and Infectious Disease, 61:440-445.

22. Karimuribo, E. D.; Morrison, L. J.; Black, A.; Turner, C. M.; Kambarage, D. M., Ballingall, K. T. (2011). Analysis of host genetic factors influencing the prevalence of African trypanosome species in Bos indicus cattle in Tanzania. Vet Parasitol, 179: 35-42. 